\title{
GENERALIZED LÜDERS OPERATION FOR NORMAL STATES ON A VON NEUMANN ALGEBRA
}

\author{
KATARZYNA LUBNAUER*, ANDRZEJ ŁUCZAK** AND HANNA PODSȨDKOWSKA*** \\ Faculty of Mathematics and Computer Sciences, University of Łódź \\ ul. S. Banacha 22, 90-238 Łódź, Poland \\ *E-mail: lubnauer@math.uni.lodz.pl \\ **E-mail: anluczak@math.uni.lodz.pl \\ ***E-mail: hpodsedk@math.uni.lodz.pl
}

Abstract. A generalized Lüders operation on states of a von Neumann algebra is considered, and the fixed points of this operation are investigated. In particular, a description of the fixed points is obtained for arbitrary semifinite von Neumann algebras, generalizing thus the one obtained for the full algebra. There is some similarity between the results for the Lüders operation on states and the results for the analogous Lüders operation on the algebra, however, the analogy is not complete and the difference is already seen for the full algebra.

Key Words and Phrases: Lüders operation, von Neumann algebra, fixed-points.

2010 Mathematics Subject Classification: 46L30, 46L55.

\section{REFERENCES}

[1] A. Arias, A. Gheondea, S. Gudder, Fixed points of quantum operations, J. Math. Phys., 43(12)(2002), 5872-5881.

[2] P. Busch, J. Singh, Lüders theorem for unsharp quantum measurements, Physics Letters A, 249(1998), 10-12.

[3] K. Klimczak, A. Łuczak, Ergodic properties of Markov semigroups in von Neumann algebras, preprint.

[4] U. Krengel, Ergodic Theorems, W. de Gruyter, Berlin-New York, 1985.

[5] Y. Li, Characterizations of fixed points of quantum operations, J. Math. Phys., 52(2011), 52-103.

[6] G. Lüders, Über die Zustandsanderung durch den Messprozess, Annalen der Physik, 8(1951), 322-328.

[7] A. Łuczak, H. Podsędkowska, Lüders instruments, generalized Lüders theorem, and some aspects of sufficiency, to appear in Int. J. Theor. Phys.

[8] K.E. Thomsen, Invariant states for positive operator semigroups, Studia Math., 81(1985), 285291.

[9] L. Weihua, W. Junde, Fixed points of commutative Lüders operation, J. Phys. A, Math. Theor., 43(2010), 395206.

Received: May 22, 2015; Accepted: October 8, 2015.

Work supported by NCN grant no 2011/01/B/ST1/03994. 
